\title{
A SPECIMEN OF THE JAMAICAN VERMILEO
}

\section{By William MoRTON WheELER}

In a collection of Jamaican Diptera recently received by the Museum of Comparative Zoölogy I find what might be regarded as a topotype of the Rhagionid Vermileo tibialis (Walker). This specimen, a male, was taken by Miss Lilly Perkins at Baron Hill, near Jacksontown, Trelawny, and is interesting both because the species has not before been recovered since it was described and figured by Walker, nearly eighty years ago, in his "Diptera Sandersiana" (p. 156, Pl. 4, Fig. 3.) as the type of his genus Pheneus, and because of its very close relationship to a Cuban Vermileo which I described in my "Demons of the Dust" (1930) and in Psyche, Vol. 36, 1931, p. 167. This form I regarded as a distinct variety (dowi) of tibialis since it differed in certain respects from Walker's description and figure, which were based on a male specimen. Miss Perkins' specimen lacks the hind legs and portions of the antennæ and anterior tarsi, but there are in other portions of the body several peculiarities which show that the Cuban form is, as I inferred, at least varietally and possibly even subspecifically distinct.

The specimen is larger and more robust than the dowi males which I reared from larvæ taken by Mr. R. P. Dow in August, 1930, in the Trinidad Mountains of Cuba'. Its body and wing measure 12 and $11.5 \mathrm{~mm}$. respectively, whereas the corresponding dimensions of dowi are 9.5-10 and $8 \mathrm{~mm}$. In the Jamaican type the face and vertex are decidedly broader, the eyes less convex, the first antennal joint shorter, not more than one and one-half times as long as broad, the humeri more prominent and more acute. The body is more uniformly fulvous, the abdominal segments

\footnotetext{
${ }^{1}$ More recently, one of my students, Mr. B. B. Leavitt, collected a large number of larvae of this form at much lower elevations not far from the Atkins Laboratory of Harvard University at Soledad, near Cienfuegos, and has studied their structure, transformation and behavior.
} 
not infuscated posteriorly and the first segment bears anterodorsally a deep black, transverse band. The halteres have yellow knobs as in the Cuban variety and the wingvenation is the same, but both the membranes and the veins are more deeply fulvous and the black, transverse band across the middle of the wing is decidedly narrower, with more irregular contour.

Since we know the precise locality in which Miss Perkins took her specimen it should now be easy to find the larvæ, which make their pits like the ant-lions in sand or dust under overhanging rocks or embankments, and to ascertain, by rearing a number of imagines of both sexes, the precise differences between the Jamaican and Cuban forms of this beautiful fly. 

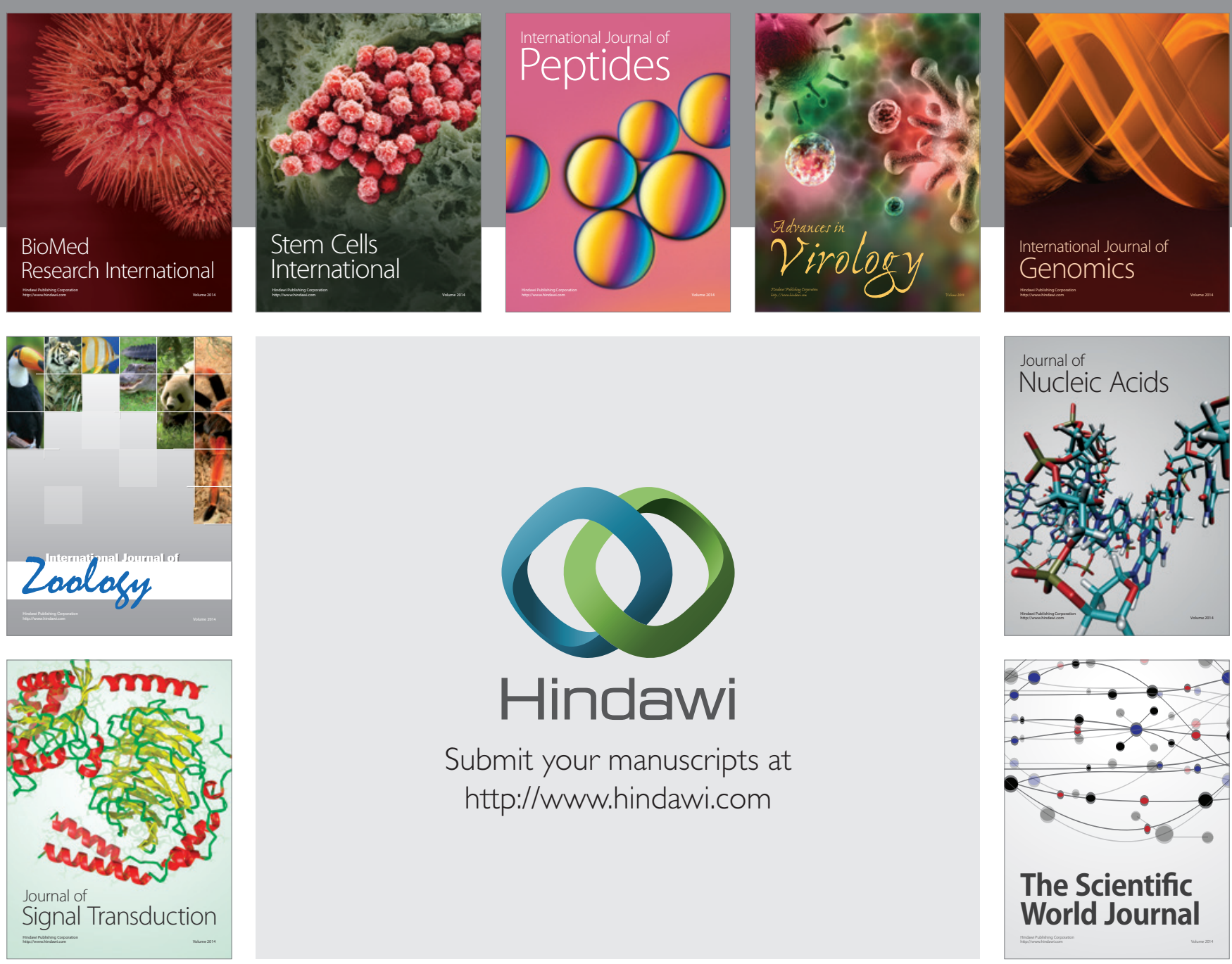

Submit your manuscripts at

http://www.hindawi.com
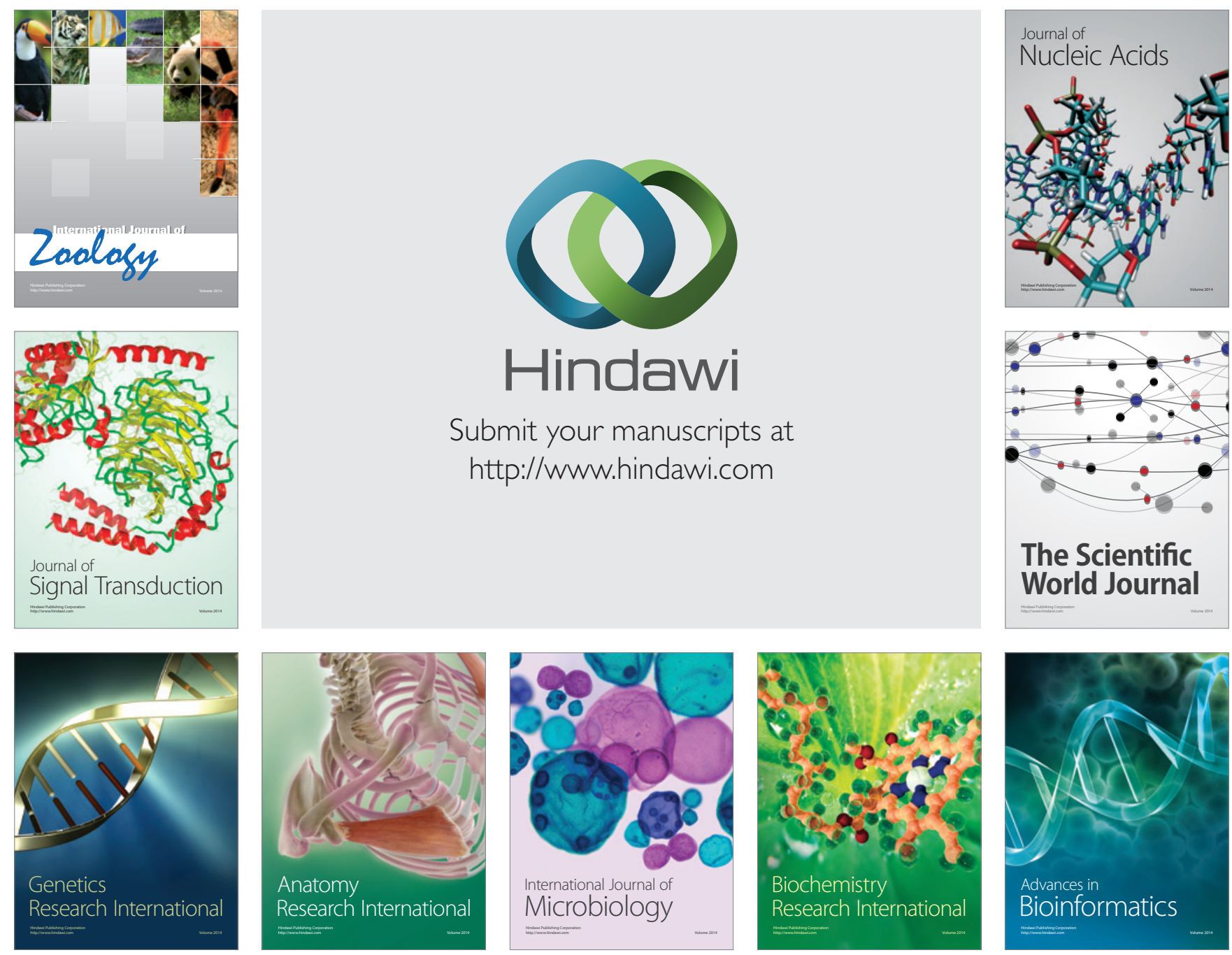

The Scientific World Journal
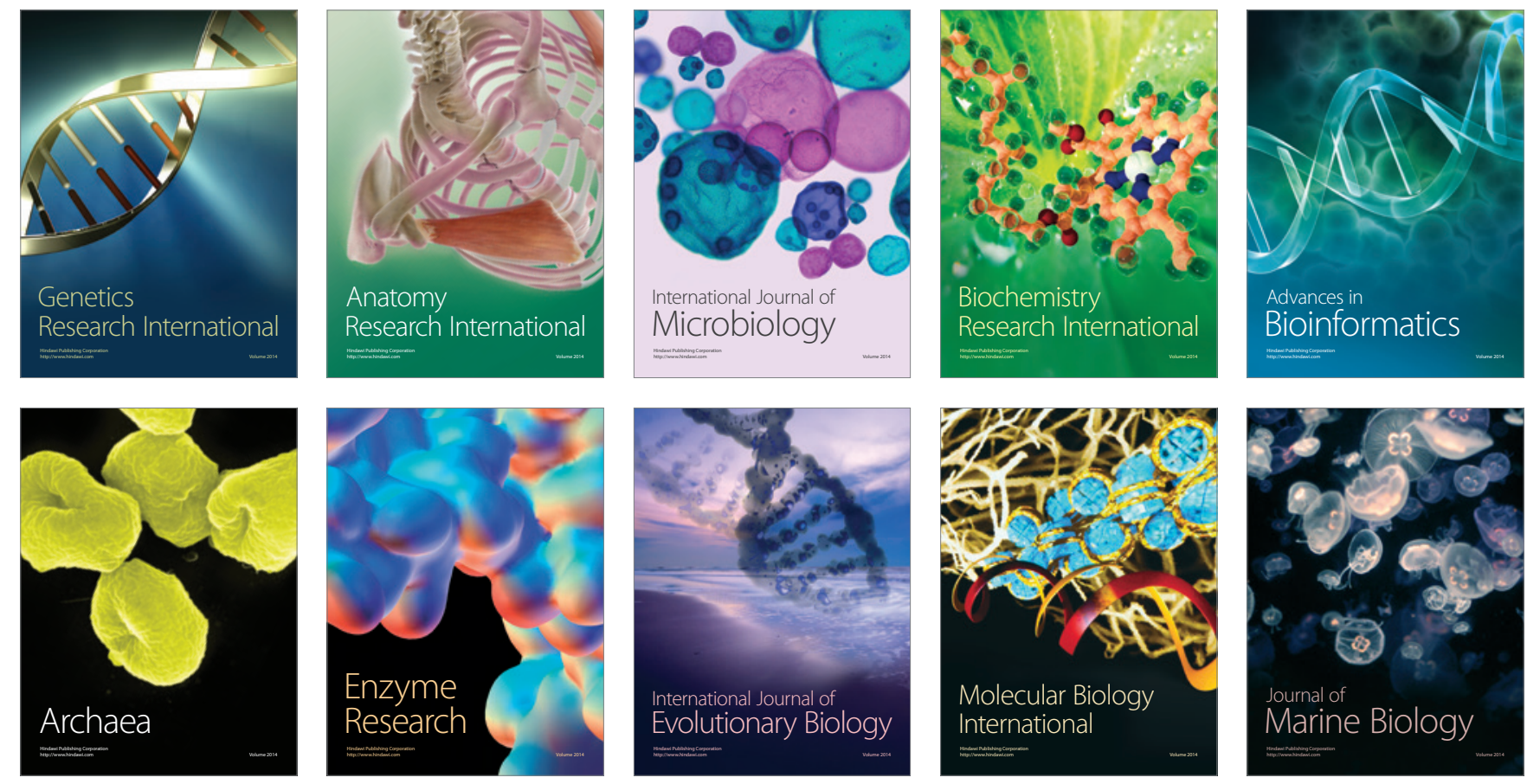